\title{
Escola e lógicas de acção organizacional: contributos teóricos para uma análise sociológica da organização educativa
}

\author{
Daniela Vilaverde e Silva
}

\section{Resumo}

Numa agenda teórica decorrente do modelo político que acentua a importância dos jogos de poder, interesses, conflitos, estratégias e coligações dos actores no quotidiano organizacional, a identificação e compreensão das lógicas de acção ou dos "mundos" que norteiam a aç̧ão emerge num registo mais actual que reafirma a pertinência deste modelo analítico no estudo das organizações educativas em geral e na escola em particular. $O$ presente artigo procura reflectir sobre os pressupostos teóricos do modelo político de análise organizacional, centralizando duas focalizações estruturais do mesmo: a) a diferenciação vs complementaridade da abordagem sistémica e estratégica de Crozier e Friedberg (1977); b) a proposta de um exercício de articulação entre a perspectiva teórica da escola das convenções e o modelo político.

Palavras-chave: Modelo político. Lógicas de acção. Convenções.
Abstract

School and organizational actions logics : theorise contributions for a sociology analyse of educative organizations In a theoretical board from political model which empathize the importance of actors' power games, interests, conflicts, strategies and colligations in the everyday of organizations, the identification and understanding of action logics or "worlds" which commands the action grow up in a actual register which reaffirms the pertinence of this model in the study of educative organizations in general and school in particular. The present article trys a reflection about the theoretical political model of organizational analyses, around two focus: a) the difference vs complementarity of system and strategic approach by Crozier and Friedberg 
(1977); b) the propose of an exercise of articulation between the theoretical of the convention school and the political model. Keywords: Political model. Actions logics. Conventions.

\section{Resumen \\ Escuela y lógicas de acción de las organizaciones : contributos teóricos para una analice sociológica de la organización educativa}

En una agenda teórica del modelo político que acentúa la importancia de los juegos de poder, intereses, conflictos, estrategias e coligaciones de los actores en lo cuotidiano organizacional, la identificación y comprensión de las lógicas de acción o los "mundos" que comandan la acción emerge como uno registro mas actual que reafirma la pertinencia de este modelo analítico en el estudio de las organizaciones educativas en general y la escuela en particular. El presente artículo procura reflexionar sobre los presupuestos teóricos del modelo político de la analice de las organizaciones, centralizando dúos focos estructuráis de lo mismo: a) la diferenciación vs complementariedad del aborde sistémica e estratégica de Crozier y Friedberg (1977); b) la propuesta de uno ejercicio de articulación entre la perspectiva teórica da la escuela de las convenciones e lo modelo político.

Palabras clave: Modelo político. Lógicas de acción. Convenciones.

\section{Introdução}

O estudo da escola como organização pressupõe a consideração de que este objecto científico de estudo se constitui como um "objecto polifacetado" (LIMA, 1996, p. 27), "políptico e multidiscursivo" (ESTÊVÃO, 1998) sujeito a uma pluralidade de focalizações teóricas, que espeIham uma heterogeneidade de ângulos que retiram a hegemonia de um só modelo, beneficiando a análise organizacional de um "diálogo" entre modelos. Desta forma, a selecção dos modelos teóricos reveste-se de uma certa complexidade analítica. Neste texto, procuraremos desenvolver alguns dos pressupostos do modelo político de análise das organizações, articulando-o com uma outra proposta teórica: a escola das convenções.

modelo político abala com determinados pressupostos teóricos do modelo burocrático weberiano, substituindo algumas das suas dimensões estruturantes. A racionalidade olímpica das teorias clássicas cede lugar a uma "racionalidade limitada" (SIMON, 1983), a previsibilidade é posta em causa ao introduzir-se a incerteza/ imprevisibilidade nas dinâmicas da organização (THOMPSON, 1967), o conceito de poder formal/legal passa a ser conceptualizado como uma das formas de poder. Deste modo, o processo de tomada de decisão já não se torna tão claro, mas antes um processo conflitual e moroso. A consideração de valores/metas/objectivos universais, acompanhados de estruturas estáveis comandadas por uma racionalidade absoluta, é substituída por uma nova concepção organizacional que enfatiza a pluralidade valores/interesses/objectivos e racionalidades dos actores organizacionais. 
modelo político concebe as organizações como "sistemas de actividade política" (MORGAN, 1996, p. 152), onde os valores e a diversidade de interesses fervilham no quotidiano da actividade das organizações dando origem por vezes a conflitos e à concepção de jogos de poder. Estes jogos de poder encontram-se escondidos no interior das organizações, sendo por vezes ocultados pelos actores, que procuram mascarar e dissimular os seus interesses, poderes, estratégias e até conflitos.

A aplicação do modelo político à organização escolar constitui uma das dimensões complementares para a compreensão e desmontagem das práticas dos actores organizacionais no que converge, sobretudo, às dimensões mais micro-analíticas. Nesta acepção, a perspectiva micropolítica torna-se imprescindível para uma melhor compreensão das dinâmicas, das lógicas de acção dos actores que se desenvolvem na organização escolar, uma vez que esta pode ser concebida como "uma entidade política, quer dizer, como um sistema construído por indivíduos e grupos em interacção, que perseguem interesses diferentes [...] defendem distintas ideologias através do uso do poder e de outros recursos" (GONZÁLEZ GONZÁLEZ, 1994, p. 50-51).

\section{Modelo político e lógicas de ação em contexto organizacional escolar}

A conceptualização das lógicas da acção remete-nos para a compreensão dos sentidos norteadores da acção dos actores em contexto organizacional. As lógicas de acção podem ser definidas como "conteúdos de sentido, relativamente estáveis e consolidados, com que os actores sociais interpretam e monitorizam a acção nas organizações escolares, ordenando, ainda que de forma precária e provisória, a realidade organizacional aparentemente fragmentada e dispersa" (SARMENTO, 2000, p. 147). Neste sentido, pretender situar os diferentes significados expressos pelas acções organizacionais exige, por um lado, interpretar todo o universo simbólico subjacente às acções e por outro lado, estudar e situar esses universos simbólicos na rede de relações sociais estabelecidas pelos actores organizacionais que constituem os "sistemas de acção concretos" (CROZIER; FRIEDBERG, 1977) das organizações.

A noção de "sistema de acção concreta", por sua vez, implica a apropriação dos conceitos de acção social e de poder. $\mathrm{Na}$ política da acção colectiva "não há campo neutro nem estruturado na medida em que não há acção social sem poder, e que todo o poder supõe e constitui estruturação do campo, ou seja, uma regulação dos comportamentos dos actores implicados" (FRIEDBERG, 1995, p. 115).

Estudar a genealogia do conceito de acção social implica evocar Weber como um dos primeiros teóricos a debruçar-se sociologicamente sobre a construção da análise da acção social entendida como "aquela em que o sentido intentado pelo agente ou pelos agentes está referido ao comportamento de outros e por ele se orienta no seu decurso" (WEBER, 1997, p. 21). Dito de outro modo "orienta-se pelas acções dos outros"1. Se adoptarmos a distinção entre os conceitos de acção, indutora de actividade do conceito de social, parece-nos redutora uma

1 WEBER, M. Fundamentos da sociologia. Lisboa: Ed. Rés, 1983. p. 73. 
concepção de acção que se oriente somente pelas normas. De acordo com a definição apresentada por Weber (1991), a acção implica uma relação e uma orientação de alguém sobre outrem que possibilita a identificação do "sentido subjectivo"2 atribuído pelos actores.

Neste ponto, Crozier e Friedberg (1977) encontram-se com Weber (1991) ao considerarem que o poder é um conceito que implica uma relação e não constitui um atributo do sujeito. A acção social ${ }^{3}$ weberiana encontra os seus fundamentos em quatro lógicas de acção ${ }^{4}$ : a acção tradicional; a acção racional em relação aos fins organizacionais; a acção racional em relação aos valores; e a acção baseada na afectividade (WEBER, 1983, p. 75-76), estabelecendo-se uma ruptura com uma concepção unitária de lógicas de acção. Podemos assim afirmar que Weber lançou os pilares do pensamento sobre o conceito de acçãosocial, sobre o qual repousa o conceito de lógicas de acção.

Na lógica política, "na sua essência, uma lógica de acção pode ser entendida como a relação implícita (isto é, muitas vezes não declarada) entre meios e objectivos que é assumida pelos protagonistas nas organizações." 5 Num contexto complexo regido pela imprevisibilidade e pluralidade de interesses dos actores organizacionais, próprio do modelo político, as lógicas de acção tornam-se mais difíceis de desvendar, no que concerne aos objectivos e às tecnologias ou meios que permitem alcançá-los.

Nesta sequência,

a selecção dos objectivos, dos meios e da lógica cognitiva que os une pode facilmente transformar-se na fonte da actividade política dentro das organizações. De facto, as políticas podem reduzir-se ao debate, à negociação e ao conflito sobre a lógica de acção que se manifesta como as regras da decisão que unem os objectivos e os meios para os membros da organização. (BACHARACH; MUNDELL, 1999, p. 127).

Seguindo esta linha, a racionalidade das lógicas de acção encontram-se dependentes do sentido atribuído pelo actor à acção de forma a desconstruir as finalidades e intenções norteadoras da acção dos actores organizacionais.

Assim, compreender as lógicas de acção dos indivíduos concorre, neste sentido, para a explicitação dos conflitos de poder, dos jogos de interesses dos protagonistas. No pensamento de Bernoux (1999, p. 47): "o paradigma das lógicas de acção foi criado para dar conta da diversidade das interpretações possíveis dos fenómenos observados [...] são uma maneira de definir o sentido que o actor dá à sua acção".

No contexto da organização escolar, Bacharach e Mundell (1999) apresentam

\footnotetext{
${ }^{2} \mathrm{O}$ "sentido subjectivo" da acção fornecido pelos actores permite clarificar a distinção entre acção e actos espontâneos desprovidos de racionalidade.

${ }^{3}$ Para Weber nem toda a acção é social. Segundo o autor, "a conduta intima só é acção social quando determinada pelas acções dos outros" (WEBER, 1983, p. 73) e só tem caracter social quando é "dirigida à acção dos outros".

${ }^{4}$ Apesar desta diferenciação das lógicas de acção, Weber não procurou hierarquizá-las mas antes analisá-las.

5 "as lógicas de acção encaradas como conteúdos específicos que orientam o comportamento não podem ser explicadas ao nível da organização ou do sistema económico; elas pertencem ao domínio do simbólico que, além do mais, não se encontra (KARPIK, 1978, p. 59 apud BACHARACH; MUNDELL, 1999, p. 127).
} 
duas lógicas de acção que os docentes podem manifestar: a lógica da responsabilização burocrática e a lógica da autonomia profissional. Sem descurar o contexto administrativo em que as organizações escolares se encontram, que determina/condiciona a lógica de acção predominante dos actores escolares, a consideração destas duas lógicas de acção mostra que elas representam as possibilidades de acção conferidas aos actores organizacionais pautadas quer pelo modelo burocrático quer pelo modelo político. Neste sentido, a lógica de acção da responsabilidade burocrática, congruente com o modelo burocrático weberiano, caracteriza-se pela definição clara das relações entre meios-objectivos, pressupondo que estas "podem limitar a incerteza de uma forma racional" ${ }^{6}$

Numa posição oposta, imbricada ao modelo político, os autores desenvolvem a lógica da autonomia profissional que considera a incerteza como "algo que se impregna nas organizações e que não pode ser eliminada facilmente por uma definição racional e pela especificação das relações meios-objectivos". 7

Ainda no âmbito do estudo da acção organizacional, Lima (1998) fornece-nos um contributo importante para a distinção conceptual das dimensões imbricadas na acção. Partindo do estudo da organização escolar, o autor concebe duas distinções fun- damentais que norteiam a acção organizacional: o "plano das orientações para a acção organizacional" e o "plano da acção organizacional". Com base nesta distinção, poderemos analisar a acção sob dois planos que, em determinados momentos, podem coincidir e, noutros, assumirem formas tão dispares, que a articulação entre eles se torna débil e ambígua. Assim, de acordo com o quadro n. ${ }^{\circ}$ 1, o "plano das orientações para a acção organizacional" situado nas estruturas quer "latentes" quer "ocultas" (que o autor também denomina de "cripto-estruturas") corresponde à produção das regras organizacionais que regem a acção dos actores, podendo estas serem consideradas a nível mais "superfici$\mathrm{al}^{\text {", }}$ materializado pela existência de "regras formais" (produzidas fora da organização), a nível "intermédio", constituído pelas "regras não formais" (produzidas no contexto da organização) e ainda a nível de análise mais "profundo", composto pelas "regras informais" (produzidas em contexto organizacional pelos actores, raramente escritas e nem sempre aplicadas por todos, sendo por vezes assumidas como formas de não cumprimento das regras formais).

$\bigcirc$ "plano da acção organizacional" situa-se na estrutura "manifesta", ou seja, na acção propriamente dita, na qual as regras são "efectivamente actualizadas", praticadas pelos actores organizacionais. Foi neste plano que o autor desenvolveu a

\footnotetext{
${ }^{6}$ BACHARACH, S.; MUNDELL, B. Políticas organizacionais nas escolas ... In: SARMENTO, M. J. (Org.). Autonomia da escola ... Porto: Ed. ASA, 1999. p. 127.

${ }^{7}$ lbid., 1999, p. 127. Os autores desenvolvem esta conceptualização das lógicas de acção integrando-as no âmbito das reformas educativas realizadas nas escolas e áreas educativas ocorridas nos Estados Unidos da América. Segundo os autores, o objectivo ideológico da excelência, "definida como a oportunidade de todos poderem competir em igualdade de condições para o acesso à escola [...] é colocada em paralelo com o meio ideológico da estandardização, sendo este ultimo encarado como nivelador de uma competência justa" (Ibid., 1999, p. 128). Clarificam-se, assim, as relações entre objectivos e meios, próprios da lógica de acção da responsabilidade burocrática. No âmbito oposto da lógica de acção da autonomia profissional, o objectivo defendido mais congruente é o da equidade e "relaciona-se com o meio ideológico da participação, permitindo aos profissionais a autonomia para compensar as diferenças individuais entre estudantes, de forma a evitar tratar como iguais os que não o são".
} 
sua teoria sobre o "modo de funcionamento díptico da escola como organização", que se rege segundo dois modelos fundamentais: o modelo burocrático weberiano, que enfatiza a "reprodução" da "regras formais" e o modelo de "ambiguidade/anárquico" que centraliza a "produção" das "regras não formais" e "informais".

autor acrescenta ainda que pretender analisar estes dois planos pressupõe, numa primeira análise, conhecer a estrutura "latente" da organização através de uma focalização "normativa", enquanto que a compreensão da estrutura "oculta" exige uma "focalização" de análise "interpretativa" das regras nãoformais e informais. A estrutura "manifesta", situada no "plano da acção", é alvo de uma "focalização descritiva" dos diferentes desempenhos dos actores através da actualização de regras conforme comprovamos com o seguinte quadro apresentado pelo autor:

\begin{tabular}{|c|c|c|c|c|}
\hline $\begin{array}{c}\text { Planos } \\
\text { organizacionais } \\
\text { analíticos }\end{array}$ & $\begin{array}{c}\text { Estruturas } \\
\text { organizacionais }\end{array}$ & $\begin{array}{c}\text { Regras } \\
\text { organizacionais }\end{array}$ & $\begin{array}{c}\text { Níveis } \\
\text { organizacionais }\end{array}$ & $\begin{array}{c}\text { Tipos de } \\
\text { focalização } \\
\text { analítica }\end{array}$ \\
\hline \multirow{3}{*}{$\begin{array}{c}\text { Plano das orientações } \\
\text { para a acção } \\
\text { organizacional }\end{array}$} & Latentes & Formais & Superficial & Normativa \\
\hline & Ocultas & Não-formais & Intermédio & \multirow{2}{*}{$\begin{array}{l}\text { Interpretativa } \\
\text { (scricto sensu) }\end{array}$} \\
\hline & (cripto-estruturas) & Informais & Profundo & \\
\hline $\begin{array}{l}\text { Plano da acção } \\
\text { organizacional }\end{array}$ & Manifestas & $\begin{array}{c}\text { Efectivamente } \\
\text { actualizadas }\end{array}$ & Manifesto & Descritiva \\
\hline
\end{tabular}

Quadro 1 - Proposta teórico-conceptual para a análise organizacional da escola. Fonte: Lima (2001, p. 57).

No campo teórico da conceptualização das lógicas de acção, Dubet (1996, p. 112 137) é outro autor de referência no estudo de acção organizacional que nos apresenta três lógicas de acção: a lógica da integração, a lógica de acção estratégica e a lógica de acção da subjectivação. Para este autor, "cada actor individual ou colectivo, adopta necessariamente estes três registos de acção que definem simultaneamente uma orientação visada pelo actor e uma maneira de conceber as relações com os outros". ${ }^{8}$

A lógica de acção pautada pela integração é a mais congruente com os pres- supostos da sociologia clássica, sendo a identidade do actor organizacional "a maneira como o actor interiorizou os valores institucionalizados por meio dos papéis".?

A lógica de acção estratégica define a identidade do actor "em termos de estatuto, no sentido que Weber dá a este conceito [...] designando o estatuto, a posição relativa de um indivíduo, quer dizer, a 'probabilidade' que ele tem de influenciar os outros graças aos meios ligados a esta posição". ${ }^{10}$

Nesta lógica, a identidade já não é fixa mas constantemente (re)construída pelos

${ }^{8}$ DUBET, F. Sociologia da experiência. Lisboa: Inst. Piaget, 1996.

9 Ibid., 1996, p. 115.

${ }^{10}$ lbid., 1996, p. 121. 
actores organizacionais, num campo de forças onde se desenrolam os jogos de poder. De acordo com F. Dubet"1 " "a integração do sistema é substituída pela sua regulação, pela necessidade de manter as regras do jogo para que o jogo seja possível. A civilidade e a pertença ao grupo são, não já uma norma, mas uma [...] condição necessária à prossecução dos objectivos".

Contudo, apesar da aparente contradição entre estas duas lógicas apresentadas, elas acabam por serem complementares, uma vez que a acção estratégica "não é possível sem o apoio de uma integração mínima"12, cruzando desta forma os contributos da sociologia durkheimiana com os pressupostos da análise estratégica. $\bigcirc$ jogo só se legitima pelo mínimo de integração na organização e pelo conhecimento do outro, podendo este ser considerado quer como um rival, quer como um aliado. Nesta lógica "as relações sociais são definidas em termos de concorrência de rivalidade mais ou menos viva dos interesses individuais ou colectivos"13, funcionando sobre a égide da metáfora do mercado ${ }^{14}$.

A lógica da subjectivação nasce da crítica às concepções de homem que emergiram das lógicas anteriores, pressupondo que "o indivíduo não é redutível nem aos seus papéis nem aos seus interesses". A identida- de do sujeito é construída através da actividade crítica, pelo "empenhamento em modelos culturais que constroem a representação do sujeito". ${ }^{15}$ Esta representação é considerada como algo inacabado, nas palavras do autor, como uma "paixão impossível e desejada". O combate à ordem social, característica desta lógica, é obtida pelo conceito de alienação, sendo definida como a "privação da capacidade de ser sujeito". ${ }^{16}$

No âmbito desta tipologia apresentada por Dubet (1996) procuraremos, de seguida, desenvolver a lógica de acção estratégica uma vez que esta nos parece a mais congruente com uma concepção de escola como "arena política" onde se desenvolvem e contextualizam as estratégias e tácticas levadas a cabo pelos actores organizacionais e nas quais importa desvendar os seus significados e intenções de forma a conhecer a(s) suas racionalidade(s).

\section{A abordagem estratégica e a abordagem sistémica: duas dimensões complementares}

A referência e a consideração dos contributos da sociologia da acção social weberiana, que nos permitem balizar os fundamentos téoricos da acção racional, es-

\footnotetext{
${ }^{11}$ DUBET, F. Sociologia da experiência. Lisboa: Inst. Piaget, 1996, p. 123-124.

12 lbid., 1996, p. 124.

13 lbid., 1996, p. 124.

${ }^{14}$ Dubet (1996, p. 129) adverte para possíveis confusões entre a sociologia da acção estratégica e as ideologias do capitalismo, nas palavras do autor: "a acção estratégica tem muitas vezes surgido como a principal ameaça e como a própria figura da alienação moderna: anomia, egoísmo, guerra de todos contra todos [...] Mais grosseiramente ainda, ela foi identificada com a ideologia do capitalismo. Mas esta frequente postura de acusada e a vontade de desmitificar as ilusões moralizadoras, a partir do núcleo duro da acção estratégica não impedem, no entanto, que qualquer posição crítica, a partir do momento em que esta teoria se harmonize com uma versão liberal da sociedade que denuncie as tradições, os bloqueamentos, os corporativismos, as intervenções regulamentares que perturbam a formação dos estados de equilíbrio harmonioso de uma "sociedade aberta" na qual cada um disporia de um poder".

15 lbid., 1996, p. 131.

16 lbid., 1996, p. 136.
} 
pelham, ainda que de forma não exclusiva, dimensões analíticas importantes para a compreensão das estratégias de acção. No entanto, abordar a centralidade do actor, nomeadamente do actor estratégico, situado no contexto organizacional remete-nos para a compreensão dos contributos teóricos de Crozier e Friedberg (1977), os quais se debruçaram sobre desenvolvimento das inter-relações entre actor (análise estratégica) e sistema (análise sistémica) dentro de uma abordagem claramente política das organizações.

Nesta sequência, estudar o comportamento humano no seio organizacional implica ultrapassar análises mais simplistas de determinismo humano para recorrer a análises mais complexas, assentes em premissas mais realistas que conferem ao actor gozar sempre de um "mínimo de liberdade" (CROZIER; FRIEDBERG, 1977, p. 42) para "bater o sistema". Assim, a autonomia dos actores implica o estabelecimento de "negociações" das possibilidades de acção entre os actores comprometidos por determinadas escolhas, situadas num determinado contexto espacial e temporal.

Neste sentido, concebe-se a natureza humana como "contingente"17 face às margens das "zonas de incerteza" e dos recur- sos que controlam, pressupondo que as organizações constituem o "reinado das relações de poder, da influência, da compra e do cálculo", ${ }^{18}$ rompendo-se com concepções deterministas do comportamento humano. Nesta perspectiva, o

homem não podia ser considerado somente como uma mão o que supunha implicitamente o esquema tayloriano de organização, nem mesmo como uma mão e um coração como reclamam os adeptos das relações humanas. Sublinhase [...] que é também uma cabeça, quer dizer uma liberdade, um agente autónomo que é capaz de cálculo, e de manipulação e que se adapta em função das circunstâncias e dos movimentos.

À luz desta consideração, emerge a concepção de homem estratega ${ }^{19}$.

O conceito de estratégia constitui o cerne das lógicas de acção segundo o modelo político. Crozier e Friedberg (1977) construíram um conjunto de pressupostos inerentes ao conceito, com base em investigações empíricas. Neste sentido, o comportamento estratégico,

a) "raramente tem objectivos claros", 20 possuindo uma pluralidade de objectivos "ambíguos, mais ou menos explícitos e contraditórios", que mu-

\footnotetext{
${ }^{17}$ A noção de contingência foi introduzida no campo teórico da sociologia das organizações por Lawrence e Lorsch na obra "Organização e Ambiente" publicada em 1967. Esta abordagem centraliza as relações entre a organização e o ambiente externo, nas quais se elaboram transações planeadas com vista à adequação da organização ao ambiente. Esta adequação pressupõe a concepção de organização aberta, inscrita num ambiente incerto. Esta abordagem enquadra-se no modelo sistémico das organizações, corroborando a ideia da inexistência do princípio da escola clássica de administração the one best way. Com base nesta abordagem, Crozier e Friedberg (1977) atribuem ao comportamento do actor um carácter contingente face à organização e ao seu ambiente.

${ }^{18}$ CROZIER, M.; FRIEDBERG, E. L'acteur et le systéme. Paris: Èditions du Seuil, 1977. p. 45.

${ }^{19}$ Nesta acepção de comportamento humano centrada na margem de liberdade do actor, o conceito de organização também vai sofrer consequências teórico-conceptuais. Segundo Crozier e Friedberg (1977) "torna-se uma ilusão querer procurar a explicação dos comportamentos empíricos observados na racionalidade da organização, nos seus objectivos, funções e estruturas como se tratasse de um conjunto de dados aos quais os indivíduos não poderiam mais que adaptar-se e que acabariam por interiorizar para guiar a sua conduta".

20 lbid., 1977, p. 55.
} 
dam conforme o decurso da acção;

b) é sempre activo, uma vez que "mesmo a passividade é sempre em certa maneira o resultado de uma escolha";

c) "tem sempre um sentido" racional relativamente às oportunidades conferidas ao actor e em relação ao comportamento dos outros actores;

d) comporta dois aspectos: ofensivo e defensivo com vista a alargar a margem de liberdade do actor e a sua capacidade de acção;

e) não é "irracional".

A conceptualização da estratégia permite enquadrar o conceito no estudo das racionalidades presentes na organização, embora com especificidades inerentes à constituição de jogos de poder dos actores organizacionais. Neste sentido, a racionalidade estratégica consiste na desocultação das "regularidades dos comportamentos observados empiricamente", conferindo sentido na relação da acção com a noção de estratégia. Contudo, isolar o actor do contexto organizacional significaria depurar o comportamento estratégico de racionalidade, o que não corresponde à concepção proposta por Crozier e Friedberg (1977). Neste sentido, a análise estratégica "obriga a procurar no contexto organizacional a realidade do actor e a compreender a construção organizacional" dos jogos estabelecidos pelos actores escolares. Opera-se, assim, a passagem de uma perspectiva passiva para uma perspectiva activa do comportamento dos actores organizacionais.

Desta forma, o comportamento estratégi$\mathrm{co}$, para ser racional, necessita de ser investigado no seio das relações entre os diferentes actores organizacionais que constróem a estrutura informal da organização, mais concretamente os "sistemas de acção concretos".
$\mathrm{Na}$ esteira dos trabalhos desenvolvidos por Crozier e Friedberg (1997), Bernoux ([198-], p. 127-128), apresenta três postulados da análise estratégica. $\bigcirc$ primeiro postulado parte do princípio que

os homens nunca aceitam ser tratados como meios ao serviço de fins que os organizadores fixam para a organização. Cada um tem os seus objectivos, os seus fins próprios. [...] Não há portanto uma racionalidade única. Cada um persegue os seus próprios objectivos e a organização vive com esta multiplicidade mais ou menos antagônica.

\section{segundo postulado refere-se}

à liberdade relativa dos actores. Numa organização, qualquer actor guarda uma possibilidade de actuação autónoma, que utiliza sempre mais ou menos [...] Se os actores são autónomos, eles comprometem a sua autonomia em zonas mal regulamentadas na organização. Estas autonomias combinam-se em jogos de poder, o poder central tentando controlar a autonomia dos actores que, por sua vez tentam escapar-lhe (BERNOUX, [198-], p. 127-128).

terceiro postulado contextualiza a estratégia no âmbito dos jogos de poder, definindo-a, de forma idêntica a Crozier e Friedberg (1977), como sendo dotadas de "racionalidade, mas dentro de uma racionalidade limita$\mathrm{da}^{\prime \prime}$, recusando a previsibilidade do comportamento humano, uma vez que o fundamento da autonomia relativa dos actores reside na imprevisibilidade. Nas palavras de Bernoux ([198-], p. 148): "é preciso que o uso desta autonomia não seja previsível" e o actor possa jogar o seu jogo nas zonas de incerteza da organização. A compreensão do contexto em que se desenvolve a estratégia é também im- 
portante para a compreensão das racionalidades subjacentes à acção, sempre num quadro de racionalidade limitada e contingencial.

Nesta contextualização, a análise estratégica e a análise sistémica articulam-se e complementam-se na análise organizacional apesar da sua natureza potencialmente contraditória.

Assim, enquanto que o raciocínio estratégico é um raciocínio de "descoberta, um raciocínio heurístico à volta do qual se elaboram e verificam as hipóteses cada vez mais gerais sobre as características do conjunto" (CROZIER; FRIEDBERG,1977, p. 234), a partir sobretudo da identificação das estratégias e da compreensão do jogo desenvolvidos pelos participantes de ambas as partes, o raciocínio sistémico procura conhecer o "sistema das relações das acções que orientam fortemente os actores, limitando os objectivos que estes podem racionalmente propor" ${ }^{21}$

Seguidamente, apresentamos as principais diferenças entre estes dois tipos de abordagem.

\begin{tabular}{|c|c|c|}
\hline & Análise estratégica & Análise sistémica \\
\hline $\begin{array}{l}\text { Ponto de } \\
\text { partida }\end{array}$ & $\begin{array}{l}\text { - parte do actor para descobrir o } \\
\text { sistema }\end{array}$ & $\begin{array}{l}\text { - parte do sistema para se encontrar } \\
\text { com o actor }\end{array}$ \\
\hline $\begin{array}{l}\text { Lógicas de } \\
\text { compreensão } \\
\text { dos fenómenos }\end{array}$ & $\begin{array}{l}\text { - indutiva; fundada sobre o modelo } \\
\text { de negociação e de cálculo }\end{array}$ & $\begin{array}{l}\text { - dedutiva; prevalece a lógica de } \\
\text { finalidade e concorrência. }\end{array}$ \\
\hline $\begin{array}{l}\text { Objecto } \\
\text { de análise }\end{array}$ & $\begin{array}{l}\text { - procura-se o cálculo que cada ac- } \\
\text { tor realiza para vingar os seus in- } \\
\text { teresses na negociação conduzida } \\
\text { com os seus parceiros }\end{array}$ & $\begin{array}{l}\text { - procura-se o enquadramento } \\
\text { coerente e as finalidades dos } \\
\text { jogos exibidos pelos actores }\end{array}$ \\
\hline $\begin{array}{l}\text { Modelo } \\
\text { implícito }\end{array}$ & - modelo de jogo & $\begin{array}{l}\text { - modelo mecanicista de } \\
\text { determinismo funcional }\end{array}$ \\
\hline $\begin{array}{l}\text { Criticas } \\
\text { Fundamentais }\end{array}$ & $\begin{array}{l}\text { - sem justificação sistémica, a análi- } \\
\text { se estratégica não passa de uma } \\
\text { interpretação fenomenológica. }\end{array}$ & $\begin{array}{l}\text { - Sem verificação da análise estratégica, } \\
\text { - a análise sistémica é especulativa; } \\
\text { - a análise sistémica pode incorrer } \\
\text { no perigo de elaborar uma simples } \\
\text { e mera descrição geral dos jogos; } \\
\text { - a análise sistémica ignora a } \\
\text { liberdade dos actores; } \\
\text { - a análise sistémica ignora o } \\
\text { carácter contingente e construtivo } \\
\text { das organizações. }\end{array}$ \\
\hline
\end{tabular}

Quadro 2 - Principais diferenças entre análise estratégica e a análise sistêmica. Fonte: Quadro construído a partir de Crozier e Friedberg (1977).

${ }^{21}$ CROZIER, M.; FRIEDBERG, E. L'acteur et le systéme. Paris: Èditions du Seuil, 1997. p. 235. 
Da leitura do quadro, salienta-se o carácter diferenciador, mas também complementar das duas abordagens. Compreender as estratégias dos actores organizacionais, no contexto do(s) jogo(s) que se vão estabelecendo no quotidiano das organizações, através da análise das inter-relações nos "sistemas de regulações conjuntas" construídas a partir das regularidades, permite identificar e compreender os "sistemas de acção concretos" pelos quais se regem.

Relativamente a este conceito, Crozier e Friedberg (1977, p. 286, grifo do autor), definem "sistema de acção concreto" 22 como

um conjunto humano estruturado que coordena as acções dos seus participantes pelos mecanismos de jogos relativamente estáveis e que mantêm a sua estrutura, quer dizer, a estabilidade dos seus jogos e as relações entre eles por mecanismos de regulação que constituem outros jogos.

Neste sentido, podemos concluir que, apesar de o raciocínio estratégico e o raciocínio sistémico assentarem em pressupostos e campos de análise diferentes, é importante ressalvar a ideia da complementaridade teórica entre ambas as análises para que se possa desocultar a racionalidade do comportamento humano e para o desenvolvimento dos referenciais dos "sistemas de acção concretos". É nos sistemas de acção concretos que o investigador pode desvendar as estratégias e táticas que os actores podem mobilizar para concretizarem os seus interesses.
Desta forma, as estratégias e as tácticas constituem um objecto de estudo aliciante para o investigador. Para compreendermos e interpretarmos as diferentes estratégias, temos de recorrer à perspectiva micro-política que fornece "informação sobre os processos implicados na manutenção, reprodução e extensão do controlo e sobre os processos de conflitos, oposições e lutas que se estabelecem contra o dito controlo" (BALL, 1993, p. 209).

A análise estratégica confere visibilidade aos processos dinâmicos das organizações, enfatizando, sobretudo, as dimensões mais ocultas, muitas vezes mascaradas e dissimuladas, da acção dos actores organizacionais. É, sobretudo, a partir do estudo e da compreensão da estratégia que poderemos identificar no contexto da acção a forma como, na linha de Hoyle (1988) os actores "individualmente ou em grupo, rentabilizam os seus recursos de poder e influência a favor dos seus interesses".

Adoptando como pressuposto teórico da perspectiva micro-política, a definição complexa de tomada de decisões, onde a disputa constitui o motor para desencadear todo um processo de forças e mobilização de diferentes tipos de recursos, a(s) estratégia(s) configuram-se como meios, caminhos a que os actores recorrem para a prossecução dos seus interesses. Esta perspectiva, através do contributo conferido pela análise estratégica, mobiliza as (des)articulações entre os jogos de influência manifestados pelos actores, que se

\footnotetext{
22 Segundo os autores, é possível que existam confusões entre este conceito e o conceito de "sistema social". Entre eles existem diferenças estruturantes uma vez que o sistema social "aparece como um dado natural, mas na medida onde não se pode provar a sua existência nem apreender os seus mecanismos de regulação. Podem-se fazer hipóteses sobre estes mecanismos, mas eles são sempre [...] ou muito especulativos e constituem projecções sobre a realidade de modelos a priori". Por sua vez, os sistemas de acção concretos constituem sistemas "cuja existência e modo de regulação podem ser demonstrados empiricamente. Por outro lado, podemos chamar sistema de acção dentro da medida onde se pode considerar como uma solução aos problemas da acção colectiva, aos problemas da interdependência, da cooperação e do conflito" (CROZIER; FRIEDBERG, 1977, p. 286).
} 
desenvolvem paralelamente com o jogo de autoridade formal da organização. No campo político da acção estratégica, os actores podem mobilizar "estratégicas individuais, de grupo ou coligações no sentido de influenciarem o processo de tomada de decisões para uma escolha preferida" (GOMES, 1993, p. 68). Os actores organizacionais são considerados, nesta linha teórica, como "actores políticos com as suas próprias necessidades, objectivos e estratégias para alcançar esses objectivos" (BACHARACH, 1988, p. 279).

desenvolvimento de estratégias grupais entronca na necessidade de compreendermos a acção colectiva orientada por diferentes interesses conflituantes na organização que promove o estabelecimento de grupos de interesses. Partilhando interesses comuns, os grupos de interesses

desenvolvem um empenhamento activo e forte na consecução dos seus interesses [que] tendem a transformar-se em lobbies, exercendo uma influência permanente e sistemática sobre os que tomam as decisões na organização. Os interesses divergentes e a constituição de coligações conduzem necessariamente ao conflito já que a convergência política só pode ser definida em oposição a outros interesses ou coligações de interesses" (AFONSO, 1994, p. 53).

predomínio de estratégias de coligação representa a máxima expressão da acção colectiva comandada por imperativos multidimensionais de poder de influência, na luta pela obtenção do controlo de recursos e, por último, de poder formal.
As coligações constituem formas de acção estratégicas desenvolvidas nas organizações, sobretudo quando os actores partilham determinado interesse ou quando o estabelecimento da coligação é favorável para ambas as partes em termos de poder e controlo de recursos. A coligação pode ser definida como a "união de grupos de interesse que estão empenhados em atingir um objectivo comum. Baseia-se na acção conjunta de dois ou mais grupos de interesse contra outros grupos de interesse" (BACHARACH; MUNDELL, 1999, p. 139). Elas surgem fundamentalmente quando determinados "grupos de indivíduos ficam juntos para cooperar com relação a assuntos específicos, eventos ou decisões, ou então propor valores específicos e ideologias" (MORGAN, 1996, p. 158).

Com o recurso à constituição de coligações, os actores organizacionais desenham uma nova estrutura organizacional, em "relação dialética" (BACHARACH, 1988) com as distintas ideologias e interesses dos actores políticos e os distintos ambientes organizacionais. No processo de disputa pela tomada de decisão, que entretanto se transforma em "arena de conflito político [...] cada sub-grupo procura que a decisão reflita os seus interesses ${ }^{\prime 23}$. As coligações de actores articulam-se, segundo Bacharach (1988), primeiro, com a identificação de objectivos colectivos e posteriormente com a definição da estratégia mais adequada para a sua concretização. Nesta contextualização, a organização é concebida como palco de luta de distintas coligações, onde se distinguem as coligações dominantes, ou seja, "aquela que controla simultaneamente, a estrutura de autoridade e os recursos da organização", ${ }^{24}$ e a

${ }^{23} \mathrm{BACHARACH}, \mathrm{S}$. Notes on a political theory of educational organizations. In: WESTOBY, A. (Ed.). Culture and power in educational organizations. Milton Keynes, England: Open University Press, 1988.

${ }^{24}$ lbid., 1988. 
coligação ou as coligações dominadas que lutam constantemente, ou em determinados momentos, pelo poder, recorrendo concomitantemente ao poder de influência para resistir e até transformar as decisões tomadas pela coligação dominante.

A existência de uma pluralidade de interesses, a constituição de coligações leva ao estabelecimento de negociações para a tomada de decisões.

estudo da escola enquanto "sistema político em miniatura" (COSTA, 1996, p. 73) enfatiza os processos de decisão a partir da "capacidade de poder e de influência dos diversos indivíduos e grupos [que] se desenvolvem e obtêm-se, basicamente a partir de processos de negociação". As negociações exprimem a consensualidade mediada por processos de ganhos e perdas de grupos de interesses em constantes situações de litígio. Assim, a "vida escolar desenrola-se com base na conflitualidade de interesses e na consequente luta pelo poder", onde a(s) estratégia(s) constituem o mecanismo de acção despoletados pelos actores na conquista do poder formal.

estudo da análise estratégica no contexto escolar tem constituído o objecto de estudo em várias investigações no âmbito da sociologia organizacional escolar. Entre diferentes investigações salientamos um estudo realizado por Blase (1991) a professores de um "colégio" no qual se procurava aplicar a perspectiva micro-política à organização educativa. Neste estudo, o autor verificou a existência de dois tipos de estratégias utilizadas pelos directores do "colégio": estratégias de controlo e de influência (face ao ambiente externo e interno da organização) e estratégias protectoras (que servem para reduzir a vulnerabilidade dos directores à pressão dos outros, em especial dos superiores administrativos, pais e membros da comunidade, e até certo ponto professores com poder $)^{25}$. No âmbito das estratégias quer de controlo quer protectoras, o autor identificou um conjunto de tácticas que concretizam ambas as estratégias. Assim, as estratégias de controlo são concretizadas a partir das tácticas interpessoais (como a benevolência, simpatia, empatia, visibilidade), tácticas racionais (através do recurso à documentação) e ainda através de práticas coercivas. As estratégias de protecção incluem "tácticas de aquiescência" e "tácticas de fuga [avoidance]".

Num outro trabalho, Greenfield (1991, p. 162) investigou um conjunto de estratégias utilizadas pelos professores para promover um relacionamento cooperativo quer nas "interacções entre professores, quer entre o director e os professores". Estas estratégias incluíam estratégias de "partilha de informações", "clarificação de expectativas", "reconhecimento de realização", entre outras. Nas interacções entre professores podem ainda desenvolver-se estratégias de "paciência", "empatia", "concordância", "respeito" e "compreensão" (MARSHALL, 1991). Em relação às interacções entre os "superintendentes" das autoridades distritais e os professores Kleine-Kracht e Wong

\footnotetext{
${ }^{25}$ No entanto, no contexto escolar, numa análise micro-sociológica, as estratégias não são utilizadas apenas pelos professores. Também os alunos sabem contornar a autoridade do professor. Esta ideia é posicionada por Delamont (198, p. 135) quando se refere às estratégias que os alunos utilizam na sala de aula, "a primeira estratégia dos alunos consiste em descobrir o que pretende o professor e dar-lho - supondo que podem prever receber uma recompensa por isso em termos académicos, empregos ou paz e sossego. Quando não se vislumbra nenhuma recompensa por se dar ao professor aquilo que ele quer, a estratégia principal pode ser então a do 'comportamento disruptivo'".
} 
(1991) investigaram um conjunto de estratégias /tácticas "formais" e "informais" que incluíam o "uso da autoridade", "coerção" (através de sanções e criticas), manipulação de facções, entre outras. Numa investigação por nós realizada (SILVA, 2004), identificamos um conjunto de estratégias protectoras por parte dos professores de um Agrupamento de Escolas do Ensino Básico em Braga, nomeadamente, o recurso à participação dos pais/encarregados de educação e elementos das juntas de freguesia nas tomadas de decisões, legitimando-as face ao poder exercido pelo Ministério da Educação e seus órgãos desconcentrados.

recurso às estratégias e tácticas faz parte do dia-a-dia das práticas dos docentes das escolas no âmbito da heterogeneidade das interacções consoante os diferentes protagonistas, os interesses ocultos, as ideologias. Assim, o estudo das estratégias e tácticas constitui um desafio importante para o investigador que permite desvendar as dinâmicas micropolíticas da organização escolar mediante o estudo da análise estratégica.

Cada estratégia pode ocultar uma determinada lógica de acção, embora não exclusivamente. Recorrendo à perspectiva teórica das convenções, as acções dos actores organizacionais derivam de diferentes "cidades" e "mundos" que se inscrevem numa determinada linha de acção.
A "Escola das

Convenções": abordagem das justificações múltiplas nas organizações

A Escola francesa das "convenções" surgiu no final da década de oitenta. Esta escola de pensamento propõe um modelo geral pelo qual se regem as relações sociais procurando encontrar a "coordenação das acções individuais a fim de se compreender como se constitui uma lógica colectiva da acção" (ORLÉAN apud BERNOUX, 1999, p. 42) mobilizada no seio das organizações. Neste sentido, Bemoux questiona "sobre que bases se pode constituir um acordo colectivo quando os actores justificam a acção por princípios diferentes?" A resposta assenta na perspectiva teórica das convenções, que propõe um enquadramento teórico da acção organizacional rejeitando a oposição entre as explicações individuais, particulares e as explicações colectivas, uma vez que os convencionalistas "procuram os meios de construção do social nas escolhas de regras do acordo". 26

Esta linha teórica de enquadramento sociológico da acção interroga as concepções unitárias de registos de justificação, propondo novas justificações ${ }^{27}$ da acção, sendo possível a partir delas, colocar a escola no centro do debate teórico organizacional de modo a fomentar uma abordagem mais conscientizadora e esclarecedora dos diferentes registos de acção dos actores organizacionais.

\footnotetext{
${ }^{26}$ BERNOUX, P. Sociologie dês organisations: lês nouvelles approches. In: CABIN, P. (Ed.). Les organisations: etat des savoirs. Auxerre: Sciences Humaines, 1999. p. 42.

${ }^{27}$ De acordo com Derovet (1992, p. 62) as reivindicações dirigidas à escola assumiram nas últimas décadas contornos muito mais complexos. Reportando-se às constestações protagonizadas por estudantes em Maio de 1968, o autor refere que "antes de 1968, a escola era justificada por um único princípio, a igualdade de oportunidades e este princípio bastava assegurar por todo o lado a coerência do sistema. Não se encontrará mais esta simplicidade. Houve a emergência - ou re-emergência - de numerosos princípios que podem legitimar e pretender organizar a escola". Neste sentido, "Hoje, vários ideais coexistem que justificam o estabelecimento escolar: a igualdade de tratamento dos alunos [...] a adaptação ao local, a capacidade de integrar os jovens social e profissionalmente, a satisfação dos consumidores, o rendimento dos investimentos educativos e ainda o amor das crianças, etc." (DEROUET; DUTERCQ, 1997, p. 11).
} 
No contexto das diferentes racionalidades que emergem no contexto organizacional a partir de diferentes "mundos", coloca-se então a questão de saber a forma como estes se podem compatibilizar para encontrar os "acordos fundados sobre os compromissos" (BERNOUX, 1999, p. 42). No enquadramento desta pluralidade, reveste-se de primordial importância o estabelecimento da convenção, que na perspectiva de Salais (apud BERNOUX, 1999, p. 43) é definida como "um conjunto de elementos que [...] os participantes partilham num acordo comum [...] Uma convenção é um sistema de investigações recíprocas sobre as competências e os comportamentos", dos actores organizacionais. Segundo Bernoux (1999), os modos das relações sociais estabelecidas pelos actores organizacionais, do tipo das convenções, apresentam dificuldade em "harmonizar" dois modelos (ou mais) de coordenação da acção.

Na obra "De la justification: les économies de la grandeur", de Boltanski e Thévenot (1991), é apresentado e desenvolvido o modelo teórico no qual se entrecruzam a formação sociológica de Boltanski e a formação económica de Thévenot, baseado na concepção de organização comandada por lógica de acção colectiva. A materialização destas lógicas de aç̧ão são traduzidas inicialmente, sob a forma de "cidades" e posteriormente sob a forma de "mundos", conceptualizados como ideais-tipos de acção, que identificam "vários grandes princípios de legitimidade que presidem à justificação de uma acção" (BERNOUX, 1999, p. 42).

Segundo Bernoux (1999, p. 44) "as 'naturezas' ou 'cidades' são construções sociais, e neste sentido os convencionalistas inscrevem- se numa linha de reflexão já reencontrada nas teorias do actor. Mas focalizam a observação sobre os compromissos porque estas dizem o essencial sobre o funcionamento de uma organização como de uma sociedade" .

A proposta teórica apresentada por Boltanski e Thévenot (1991) remete-nos para a compreensão das lógicas de aç̧ão, nomeadamente para a identificação do "princípio superior comum" que regula as aç̧ões dos actores organizacionais, através do estabelecimento de "compromissos" que procuram anular a incerteza e os "litígios" entre os diferentes actores organizacionais. É o estabelecimento do "compromisso" que define a lógica subjacente à acção, uma vez que as acções passam a ser regidas segundo a égide de um determinado "mundo". A existência do princípio superior comum permite desenvolver as condições para a existência de acordos entre as pessoas, e na linha de $\mathrm{H}$. Amblard e outros (1996, p. 84), "é em referência a este princípio [superior comum] que as pessoas evoluem no mesmo mundo e são capazes de estabelecer as equivalências que lhes permitem estabelecer o acordo no mesmo mundo".

No caso da escola, nesta nova perspectiva, "a escola entrou irremediavelmente num universo onde os princípios de justificação são múltiplos onde se deve encontrar um modo de regulamentação que tenha em conta esta pluralidade" ${ }^{28}$ Neste sentido, a concepção de escola como organização que "pré-existe como unidade social" (DEROUET; DUTERCQ, 1997) é substituída por uma concepção de escola enquanto lugar de "desordem onde se en-

\footnotetext{
${ }^{28}$ Segundo Derovet (1992, p. 62), as regulamentações definem também a existência de compromissos entre os diferentes princípios, que "não podem fazer-se à escala mundial. A este nível a exigência é muito elevada; o compromisso deveria ser perfeitamente justificado em todos os universos de referência." Neste sentido o autor defende a descentralização do sistema educativo, para que possa funcionar "a partir dos compromissos locais. O grande beneficiário desta mudança será o estabelecimento escolar que torna a unidade da gestão fundamental ao sistema educativo".
} 
contram todas as contradições que impedem um verdadeiro acordo nacional e mais ainda um consenso sobre a educação".

Esta perspectiva reforça a idéia de que a escola constitui uma "cidade política na qual as diferentes opiniões devem poder exprimir-se livremente" de acordo com diferentes "mundos", onde se procura encontrar a "maneira como se passa desta diversidade de referências que habitam nos actores para a coerência ou pelo menos para uma relativa coordenação da acção" (DEROUET; DUTERCQ, 1997).

Na mesma linha de interpretação desta perspectiva, Estêvão (2001b, p. 31-32) considera que

a vida social consiste fundamentalmente em organizar compromissos entre os vários 'mundos' ou 'grandezas' (isto é, 'formas do bem comum legítimas') que aí se constituem e que apelam a imperativos específicos ou a modos legítimos de coordenação da acção; ou seja, a construção social parte das situações e do trabalho que os actores levam a cabo para formular uma definição comum da situação e assim dar um sentido à acção.

A interpretação desta abordagem exige a compreensão prévia das diferentes lógicas ou "mundos" bem como o esclarecimento da coordenação das acções, mobilizadas em torno de compromissos. Os mundos definidos são vários e derivam de "diferentes princípios superiores" como se evidencia no quadro 3.

\begin{tabular}{|c|c|c|c|c|c|c|}
\hline Mundos & Inspiração & Doméstico & Opinião & Cívico & Mercado & Industrial \\
\hline $\begin{array}{l}\text { Princípios } \\
\text { superiores } \\
\text { comuns }\end{array}$ & $\begin{array}{l}\text { Limita-se à } \\
\text { medida; brota da } \\
\text { inspiração }\end{array}$ & $\begin{array}{c}\text { Relações } \\
\text { pessoais, } \\
\text { hierarquia, } \\
\text { tradição }\end{array}$ & $\begin{array}{l}\text { Opinião dos } \\
\text { outros }\end{array}$ & $\begin{array}{l}\text { Pré-eminência dos } \\
\text { colectivos }\end{array}$ & Concorrência & $\begin{array}{c}\text { Objecto técnico } \\
\text { e método } \\
\text { científico, } \\
\text { eficácia, } \\
\text { mudança }\end{array}$ \\
\hline $\begin{array}{l}\text { Estado de } \\
\text { grandeza }\end{array}$ & $\begin{array}{c}\text { Espontaneidade, } \\
\text { insólito, escapa à } \\
\text { razão }\end{array}$ & Avisado, & $\begin{array}{l}\text { Reputação, } \\
\text { conhecido }\end{array}$ & $\begin{array}{c}\text { Representatividade, } \\
\text { oficial }\end{array}$ & Desejo, valor & $\begin{array}{l}\text { Mudança, } \\
\text { funcionamento }\end{array}$ \\
\hline Dignidade & $\begin{array}{c}\text { Amor, paixão, } \\
\text { criação }\end{array}$ & $\begin{array}{c}\text { Ajuda, bom } \\
\text { senso }\end{array}$ & $\begin{array}{c}\text { Desejo de } \\
\text { consideraçâo }\end{array}$ & Liberdade & Interesse & Trabalho \\
\hline Sujeitos & Criança, artistas & $\begin{array}{c}\text { Relações } \\
\text { ascendentes }\end{array}$ & Vedetas & Colectividade & $\begin{array}{c}\text { Concorrente, } \\
\text { cliente }\end{array}$ & Profissionais \\
\hline Objectos & Espírito, corpo & $\begin{array}{c}\text { Presença e } \\
\text { presentes }\end{array}$ & $\begin{array}{c}\text { Nomes, marcas, } \\
\text { mensagem }\end{array}$ & Formas legais & Riqueza & Os meios \\
\hline $\begin{array}{l}\text { Fórmulas de } \\
\text { investimento }\end{array}$ & Risco & Dever & $\begin{array}{l}\text { Renúncia ao } \\
\text { secreto }\end{array}$ & $\begin{array}{l}\text { Renúncia ao } \\
\text { particular, } \\
\text { solidariedade }\end{array}$ & Oportunismo & $\begin{array}{c}\text { Investigação, } \\
\text { progresso }\end{array}$ \\
\hline Grandeza & Singularidade & $\begin{array}{c}\text { Subordinação, } \\
\text { honra }\end{array}$ & $\begin{array}{l}\text { Identificaçáo } \\
\text { com a vedeta }\end{array}$ & Adesâo, delegaçẫo & Posse & Mestria \\
\hline $\begin{array}{l}\text { Relações } \\
\text { naturais }\end{array}$ & Sonhar, imaginar & $\begin{array}{l}\text { Educar, } \\
\text { reproduzir }\end{array}$ & Persuasão & $\begin{array}{l}\text { Conjunto de uma } \\
\text { acçáo colectiva }\end{array}$ & $\begin{array}{c}\text { Relação de } \\
\text { negócios, } \\
\text { interesses }\end{array}$ & Funcionar \\
\hline $\begin{array}{c}\text { Figura } \\
\text { harmoniosa }\end{array}$ & Imaginar & Família & Audiência & República & Mercado & Sistema \\
\hline Modelo & Aventura interior & $\begin{array}{l}\text { Cerimónia } \\
\text { familiar }\end{array}$ & Acontecimento & $\begin{array}{c}\text { Manifestação por } \\
\text { uma causa justa }\end{array}$ & $\begin{array}{l}\text { Negócios, } \\
\text { mercado } \\
\text { colectivo }\end{array}$ & Teste \\
\hline $\begin{array}{l}\text { Modo de } \\
\text { expressão de } \\
\text { julgamento }\end{array}$ & $\begin{array}{c}\text { Iluminação, } \\
\text { génio }\end{array}$ & Apreciação & Opiniẫo & $\begin{array}{l}\text { Veredicto do } \\
\text { escrutínio }\end{array}$ & Preço & Efectivo, correcto \\
\hline $\begin{array}{l}\text { Forma de } \\
\text { evidência }\end{array}$ & $\begin{array}{l}\text { Certeza da } \\
\text { intuiçâoo }\end{array}$ & Exemplo & $\begin{array}{l}\text { Sucesso, ser } \\
\text { conhecido }\end{array}$ & Texto de lei & $\begin{array}{l}\text { Dinheiro, } \\
\text { beneficio }\end{array}$ & Medida \\
\hline $\begin{array}{l}\text { Estado de } \\
\text { pequeno }\end{array}$ & Rotina & $\begin{array}{l}\text { Sem génio, } \\
\text { vulgar }\end{array}$ & $\begin{array}{c}\text { Banal, } \\
\text { desconhecido }\end{array}$ & Dividido, isolado & Perda & Ineficaz \\
\hline
\end{tabular}

Quadro 3 - Os mundos comuns (adaptado da síntese de Amblard e outros (1996, p. 88). Fonte: Boltanski e Thévenot (1991). 
Os mundos apresentados ${ }^{29}$ constituem diferentes interesses, ideologias que expressam diversas faces da acção dos actores organizacionais. Cada mundo apresenta determinadas características, consoante as categorias estabelecidas por Amblard e outros (1996), que se distinguem das restantes. Partindo da leitura do quadro, podemos verificar que, recorrendo, por exemplo, ao mundo "industrial", o princípio superior comum é o objecto técnico, a eficácia. Os profissionais (sujeitos) deste mundo atingem a dignidade através do trabalho, que constitui o meio (objecto) para alcançar a mestria (grandeza). A figura harmoniosa constitui o sistema que os profissionais accionam mediante processos de medição (forma de evidência) no alcance da eficácia, superando o estado de pequeno, ou seja, a ineficácia do sistema.

Cada mundo espelha uma determinada forma de conceber as relações sociais, comandadas por diferentes princípios orientadores dependentes das racionalidades subjacentes à acção dos actores e que poderão comprometer-se por princípios assentes na inspiração, na tradição, na reputação, na colectividade, na concorrência ou na eficácia.

A importância deste quadro teórico para o estudo da organização escolar permitenos identificar os diferentes universos simbólicos que coexistem na organização escolar. Nesta perspectiva, a organização escolar é entendida como uma organização compósita (DEROUET, 1992) onde confluem várias lógicas, vários "mundos", que vão sendo coordenados através dos "acordos" fundidos pelos actores que se vão (re)estabelecendo no espaço e no tempo.

A escola entrou irremediavelmente "num universo de várias grandezas ou de vários mundos" que proporcionam a redefinição do estudo da escola à luz de uma "definição ampla [...], integradora de diferentes genealogias e de várias concepções de bem, enfim, das várias e conflituantes orientações normativas consideradas adequadas para os actores nortearem as suas condutas" (ESTÊVÃO, 2001b, p. 70). Partindo da consideração "compósita" da escola, Estêvão (2004) argumenta que a escola recomposta localmente a partir da pluralidade de mundos e dos seus princípios reguladores (domésticos, empresariais, cívicos, mercantis ou mundiais), vai implicar que os actores escolares tenham de resolver o seus dissensos, concertando as suas posições ou num mundo diferente dos que estão em contenda ou reconhecendo a supremacia de um destes mundos em conflito.

Neste sentido, as acções dos actores no seio das organizações tornam-se racionais em função de um determinado "mundo" que se traduz na identificação da acção com o "princípio superior comum" definido pela convenção. Nas palavras de Boltanski e Thévenot (1991, p. 60) "as condutas das pessoas podem ser tidas como razoáveis, coerentes e justificáveis segundo um princípio conhecido e admitido por todos, nas diferentes motivações inconscientes e interesses escondidos".

\footnotetext{
${ }^{29}$ A existência de diferentes "mundos" não se circunscreve apenas à análise organizacional. Eles podem ser transferidos para o contexto das relações entre estado e sociedade civil. Um exemplo desta conceptualização é fornecido por Boaventura Sousa Santos (1999, p. 103-1 18) ao abordar as diferentes formas de poder social e ao conceber a existência de diferentes espaços estruturais. Segundo o autor o estado não detêm o poder absoluto mas "é hoje apenas uma entre outras formas de poder e nem sequer a mais importante" (ibid., p. 111 ). No seio da sociedade capitalista emergem "quatro modos básicos de produção de poder que se articulam de maneiras especificas". São eles: o espaço doméstico, o espaço da produção, o espaço da cidadania e o espaço mundial.
} 
À luz desta perspectiva, torna-se pertinente conhecer como se desenvolvem as formas de compromisso que se estabelecem entre os actores para que não seja posta em causa a "civilidade mínima" exigível nas sociedades democráticas. Como afirma Derovet (1996, p. 69), "a expressão das divergências não deve pôr em causa as regras mínimas que permitem a vida em comum". Seguindo esta linha, importa, então, reflectir sobre as formas de coordenação das acções que, numa agenda claramente política, implica o reconhecimento, por parte dos actores escolares, de novas formas de regulação da acção inscritas num "modo solidarista de regulação" (ESTÊVÃO, 2004) que apela para a elaboração de acordos, negociações e compromissos entre os diferentes "mundos" que compõem a organização escolar e onde os actores (re)constroem a(s) sua(s) identidade(s) e os princípios argumentativos da acção. Assim, a existência dos compromissos pode marcar a negociação de dois "mundos" ou caso a negociação não seja possível, o compromisso pode evocar, por exemplo, ainda outro "mundo" não contemplado inicialmente. Os compromissos espelham, desta forma, uma concepção organizacional marcada pela conflitualidade, pela disputa e litígios onde a sua resolução exige negociações por vezes complexas.

Desta forma, apesar de esta agenda teórica entroncar com dimensões claramente pertencentes à natureza micropolítica das organizações, torna-se pertinente convocarmos também Frieberg (1995), que reflecte e argumenta sobre esta posição relacional entre a escola das convenções, por um lado, e o modelo político, por outro. Seguidamente, propomos desenvolver as interconexões entre ambas as perspectivas.

\section{(Des)articulações entre - modelo político e a Escola das Convenções}

$\bigcirc$ enquadramento da escola das convenções, do ponto de vista da análise organizacional, no modelo (micro) político remete-nos para o estudo das suas interrelações, mediante a clarificação das convergências e divergências entre ambas as perspectivas teóricas.

A compreensão dos conflitos mobilizados por diferentes interesses, ideologias que se manifestam no exercício da acção concreta, sob a forma de estratégias, tácticas, coligações, constituição de grupos de interesses, espelham, embora de forma não exclusiva, as lógicas de acção segundo a "economia das grandezas". Contudo, a correspondência imediata entre ambas as perspectivas não é simples nem linear e o consenso quanto a esta relação também não é muito claro.

Assim, surgem algumas inquietações no recurso desta abordagem sobretudo na análise das práticas organizacionais. Para refletirmos sobre a articulação destas duas abordagens, socorremo-nos, entre outros, de Friedberg (1995, p. 265), que aponta um conjunto de incongruências a esta perspectiva teórica, procurando, contudo, justificar a complementariedade da escola das convenções com a abordagem da análise estratégica.

Segundo o pensamento de Friedberg (1995), por um lado, "tem-se a impressão que os humanos que [Boltanski e Thévenot] põem em cena agem sem malícia, sem duplicidade e sem truques, isto é, afinal sem estratégia e sem interesse", uma vez que o litígio de interesses, dos "mundos" foi superado pela 
instauração de um "princípio superior comum". Nesta sequência, esta perspectiva perpassa a ideia de que o estabelecimento de compromissos constituiu uma actividade pacífica como se as acções dos intervenientes fossem "actividades apolíticas" (FRIEDBERG, 1995) personificando uma imagem "angelical" dos actores organizacionais.

Por outro lado, Friedberg (1995, p. 266) acentua também o facto de que "a entrada numa situação de provação é, para um actor, sempre pesada de consequências sobre as suas próprias possibilidades de acção". Recorrendo à linguagem da abordagem da análise estratégica, o actor só aceitará o "compromisso" "rodeando-se do máximo de garantias de que a provação não lhe será demasiado desfavorável". Neste sentido, a opção por um determinado "mundo" ou "princípio superior comum" aquando do estabelecimento do "compromisso" será sempre "longo e apaixonado [...], pois o seu resultado vai definir a pertinência dos recursos de todas as partes interessadas".

Assim, a identificação dos actores organizacionais com determinado princípio de justificação implicaria que aqueles que se manifestam num "mundo" no estado de "pequenez" estariam subjugados ao predomínio de outros actores em estado de "grandeza". Concordando com Friedberg (1995) "não se vê [como] isto se passaria sem conflitos, sem negociações, sem resistências fortes, em resumo, sem processo de poder, com tudo o que eles implicam".

Se partirmos da hipótese de que a perspectiva de Boltanski e Thévenot (1991) se situa num plano ideal da acção, que em prol da eliminação da incerteza nas organizações, os actores comungam do mesmo "princípio superior comum" de forma harmoniosa e simplista, aceitando a hegemonia de um "mundo" em relação aos "mundos" subjectivos característicos de cada ser, então a conceptualização das lógicas de acção poderiam incorrer no perigo de serem consideradas como uma "operação meramente simbólica que não afecta de outro modo a acção" (FRIEDBERG, 1995, p. 268) ou até potenciar uma "visão consensualista" (SARMENTO, 2000) do funcionamento das organizações.

Contudo, situar as lógicas de acção num plano meramente simbólico significaria desvirtuar o sentido intentado pelos autores na elaboração desta perspectiva, ideia da qual também nos afastamos. Assim, importa situar as ordens de grandeza como agentes reguladores das acções dos actores organizacionais.

Neste sentido, abordar as lógicas de acção à luz dos "compromissos" definidos à volta de um "princípio superior comum", negociados pelos diferentes actores organizacionais, implica reflectir sobre os diferentes processos negociais e também sobre os interesses, estratégias, tácticas que os actores mobilizam e manifestam na acção. Desta forma, ultrapassando as oposições mais radicais destas duas abordagens, a análise sociológica consegue concretizar o casamento conceptual destas, fomentando uma complementaridade analítica mediada pelo compromisso. Esta posição é defendida por Amblard e outros (1996, p. 110), afirmando que

o recurso ao princípio superior comum que permite estabelecer as coordenações entre os sujeitos e os objectos não é mais do que a negociação dos particularismos de que cada um pode continuar a fazer prevalecer. Pode-se considerar que os jogos individuais ou colectivos podem con- 
tinuar a alimentar jogos, estratégias e a desenrolar controvérsia entre as diferentes partes sem contrariar uma forma de coordenação das acções com base num princípio reconhecido como superior pelos actores em presença.

A aparente descontinuidade entre a escola das convenções e o modelo político que encontra a versão mais forte em Friedberg (1995) exige, do ponto de vista conceptual e teórico, a (des)articulação dos conceitos de conflitos / compromissos e, ainda na linha de pensamento de Amblard e outros (1996), de actor/pessoa, jogos/princípio superior comum; regra/convenção. É, sobretudo, neste três últimas oposições que nos debruçaremos de seguida.

Segundo a escola das convenções, a concepção de "pessoa", no contexto organizacional, pressupõe uma capacidade de acção de acordo com vários mundos, o que torna possível uma multiplicidade de registos de comportamento. No entanto, para Amblard e outros (1996, p. 109) tanto "a pessoa como o 'actor' podem construir estratégias [...] o actor constrói os sistemas e os seus campos estratégicos. A pessoa maneja dispositivos que se manifestam na escolha do regime de acção". Assim, se a "pessoa" pode exibir vários comportamentos segundo vários registos de acção, que se inscrevem em diferentes "mundos", então a complementaridade das abordagens é possível, uma vez que os registos de acção elaboram-se num quadro de racionalidade "limitada" na qual se constrói o "sistema de acção concreta" que é regida por uma multiplicidade de estratégias que derivam de diferentes "mundos". Por outras palavras, a "pessoa" em Bolthasky e Thévénot (1991), também é um actor estratégico.
A oposição entre jogos/princípio superior comum também é possível de ser superada pela complementaridade. Seguindo a linha de Amblard e outros (1996), o princípio superior comum expressa a união dos actores em torno de um "dispositivo de acção. Todavia, os jogos podem também ser comuns entre os actores [...]". Nesta sequência, o princípio superior comum constitui uma forma de coordenação das acções assente no acordo estabelecido entre os actores sem esquecer que os jogos "individuais e colectivos podem continuar a alimentar jogos estratégicos [...] sem contrariar uma forma de coordenação das acções com base num princípio reconhecido como superior pelos actores em presença".

A dicotomia regra/convenção, apesar da complexidade analítica que os conceitos encerram, é possível de ser ultrapassada se adoptarmos a definição de uma regra, mais comumente aceite, como "princípio de referência" das acções dos actores. A regra define o padrão de comportamento a ser adoptado pelos diferentes actores, os quais podem (des)ajustar o seu comportamento em relação à regra. Nesta possibilidade os actores mobilizam "regras e jogam com elas. Neste jogo, as regras podem resultar de relações de coordenação ou de disputas, de acordo ou de controvérsias". Assim enquadrada, a oposição conceptual dissipa-se se considerarmos a convenção como "um tipo particular de regra [...] de referência, um modelo de acordo" (AMBLARD et al., 1996).

Sintetizando, a escola das convenções, tal como é proposta por Boltanski e Thévenot (1991), parece induzir uma pseudo-ruptura com os modelos sociológicos de análise organizacional, de tal 
modo que surgem acusações de "desprezar as relações anteriores da sociologia". Contudo, a complementaridade entre escola das convenções e modelo (micro) político é possível como analisámos, tendo por referência as reflexões induzidas por Amblard e outros (1996), rejeitando a posição de abandono total com os modelos organizacionais.

$\mathrm{Na}$ esteira dos trabalhos de Boltanski e Thévenot (1991), Estêvão (2001, p. 71) também argumenta que

o entendimento do espaço escolar [na linha de Boltanski e Thévenot] sublinha claramente a dimensão política e também ética da escola, que justifica a sua compreensão como arena social e política, pelo relevo dado ao poder e privilégios, aos interesses e influências, às racionalidades e argumentações, às práticas (micro)emancipatórias ou de subjugação, às dinâmicas de coordenação da acção.

Considerámos, então, que o cruzamento dos contributos da escola das convenções, integrado no modelo político mais amplo permite compreender melhor as verdadeiras dinâmicas dos actores.

\section{Em jeito de conclusão}

A adopção de um modelo de análise da organização escolar permite ao investigados seleccionar uma determinada faceta da realidade organizacional de modo a compreender os meandros desse contexto. Nesta perspectiva, o modelo político constitui uma das possíveis leituras da realidade organizacional, que embora excluindo outras dimensões, permite-nos, por um lado, conhecer os jogos que se desenrolam no interior de uma organização e, por outro, enfatizar a análise da acção social desenvolvida pelos actores organizacionais possibilitando-nos interpretar os sentidos da acção. Assim, no âmbito do estudo das lógicas de acção recorremos a uma abordagem mais actual da literatura organizacional: a escola francesa das "convenções", procurando precisar dimensões teóricas que podem cruzar com o modelo político, nomeadamente o conceito estratégia(s), coligações e convenções.

Embora conscientes da falta de consenso na articulação da perspectiva teórica das "convenções"e o modelo político, a nossa proposta enquadra-se num exercício de reflexão pela defesa desta interconexão, nomeadamente no que diz respeito à aplicação desta perspectiva ao estudo da escola (SILVA, 2004). A adopção desta perspectiva permitiu reconceptualizar a representação da escola que, do ponto de vista organizacional:

é essencialmente uma organização plural, com uma vida social mobilizada em torno de compromissos entre os vários mundos que aí se constituem, com estratégias múltiplas de justificação concretizadas pelos actores sociais escolares designadamente nas situações de litígio, com necessidades de coordenarem a sua acção concreta para que as organizações apesar de tudo funcionem (ESTÊVÃO, 2001 a, p. 18).

Em suma, podemos considerar que a escola das convenções pode constituir uma nova agenda integrada numa concepção política da sociologia das organizações. 


\section{Referências}

AFONSO, N. A reforma da administração escolar: a abordagem política na análise organizacional. Lisboa: Instituto de Inovação Educacional, 1994.

AMBLARD, $H$. et al. Les nouvelles approches sociologiques des organisations. Paris: Éditions du Seuil, 1996.

BACHARACH, S. Notes on a political theory of educational organizations. In: WESTOBY, A. (Ed.). Culture and power in educational organizations. Milton Keynes, England: Open University Press, 1988.

BACHARACH, S.; MUNDELL, B. Políticas organizacionais nas escolas: micro, macro e lógicas de acção. In: SARMENTO, M. J. (Org.). Autonomia da escola: políticas e práticas. Porto: Edições ASA, 1999.

BALL, S. La perspectiva micropolitica en el análisis de las organizaciones educativas. In: SALLÁN, J.; MARCOS, S. (Coord.). Organización escolar: nuevas aportaciones.

Barcelona: Collección Universitas, 1993.

BERNOUX, P. A sociologia das organizações. Porto: Rés, [198-].

. Sociologie des organisations: les nouvelles approches. In: CABIN, P. (Ed.). Les organizations: etat des savoirs. Auxerre: Sciences Humaines, 1999.

BLASE, J. The micropolitical perspective. In: BLASE, J. (Ed.). The politics of life in schools. Newbury Park: Sage Publications, 1991.

BOLTANSKI, L.; THÉVENOT, L. De la justification: les économies de la grandeur. Paris: Gallimard.1991.

COSTA, J. A. Imagens organizacionais da escola. Porto, PT: Asa, 1996.

CROZIER, M. ; FRIEDBERG, E. L'acteur et le systéme. Paris: Èditions du Seuil.1977.

DELAMONT, S. Interacção na sala de aula. Lisboa : Livros Horizonte, 1987.

DEROUET, J. École et justice: de l'égalité des chances aux compromis locaux?. Paris: Editions Métailié, 1992.

- funcionamento dos estabelecimentos de ensino em França: um objecto científico em redefinição. In: BARROSO, J. (Org.). O estudo da escola. Porto: Porto Editora, 1996.

DEROUET, J.; DUTERCQ, Y. L'établissement scolaire, autonomie locale et service public. Paris: ESF Editeur, 1997. 
DUBET, F. Sociologia da experiência. Lisboa: Instituto Piaget, 1996.

ESTÊVÃO, C. Educação, justiça e autonomia: os lugares da escola e o bem educativo. Porto: Asa, 2004.

. Justiça complexa e educação: as gramáticas da justiça em educação. Revista Brasileira de Política e Administração da Educação, Porto Alegre, v. 17, n. 1, p. 11-26, 2001 a.

Justiça e educação. São Paulo: Cortez Editora, 2001 b.

Redescobrir a escola privada portuguesa enquanto organização. Braga: Universidade do Minho, Instituto de Educação e Psicologia, Centro de Estudos em Educação e Psicologia, 1998.

FRIEDBERG, E. O poder e a regra: dinâmicas da acção organizada. Lisboa: Instituto Piaget, 1995.

GOMES, R. Culturas de escola e identidades dos professores. Lisboa: Educa, 1993.

GONZÁLEZ GONZÁLEZ, M. T. Perspectivas teóricas recientes en organización escolar: una panorámica general. In: ESCUDERO, J. M.; GONZÁLEZ GONZÁLEZ, M. T. Professores y escuela: ? hacia una reconversión de los centros y la función docente? Madrid: Édiciones Pedagógicas, 1994.

GREENFIELD, W. The micropolitics of leadership in na urban elementary school. In: BLASE, J. (Ed.). The politics of life in schools. Newbury Park: Sage Publications, 1991.

HOYLE, E. Micropolitics of educational organizations. In: WESTOBY, A. (Ed.). Culture and power in educational organization. Milton Keynes, England: Open University Press, 1988.

KLEINE-KRACHT, S.; WONG, K. When district autority intrudes upon the local school. In: BLASE, J. (Ed.). The politics of life in schools. Newbury Park: Sage Publications, 1991.

LIMA, L. Construindo um objecto: para uma análise critica da investigação portuguesa sobre a escola. In: BARROSO, J. (Org.). O estudo da escola. Porto: Porto Ed., 1996.

A escola como organização: uma abordagem sociológica. São Paulo: Cortez, 2001.

A escola como organização e a participação na organização escolar. Braga:

Universidade do Minho, Instituto de Educação e Psicologia, Centro de Estudos em Educação e Psicologia, 1998. 
MARSHALL, C. The chasm between administrator and theacher cultures: a micropolitical puzzle. In: BLASE, J. (Ed.). The politics of life in schools. Newbury Park : Sage Publications, 1991.

MORGAN, G. Imagens da organização. São Paulo: Atlas, 1996.

SANTOS, B. S. Pela mão de Alice: o social e o político na pós-modernidade. Porto: Afrontamento, 1999.

SARMENTO, M. Lógicas de acção nas escolas. Lisboa: IIE, 2000.

SILVA, D. Lógicas de acção em contexto de autonomia: estudo das representações docentes de um agrupamento de escolas do ensino básico. 2004. Dissertação (Mestrado)-Universidade do Minho, Braga, 2004.

SIMON, H. A. Administration et processus de décision. Paris: Economica, 1983.

WEBER, M. Conceitos sociológicos fundamentais. Lisboa: Edições 70, 1997. (Nova Biblioteca).

Economia e sociedade. Brasília, DF: Edições Universidade de Brasília, 1991. . Fundamentos da sociologia. Lisboa: Rés, 1983.

Recebido em: 19/12/2006

Aceito para publicação em: 25/05/2007 